\title{
NATUREZA URBANA E TECNOPOLÍTICAS INDISCIPLINARES
}

\author{
Natacha Silva Araújo Rena ${ }^{1}$
}

\author{
Octavio Henrique Mendes Pena²
}

Marcelo Reis Savergnini Maia ${ }^{3}$

\section{RESUMO}

Este artigo apresenta o projeto "Natureza Urbana" desenvolvido do grupo de pesquisa do CNPq denominado "Indisciplinar/UFMG" que colabora com múltiplas ações junto aos movimentos sociais e ambientais em defesa da qualidade do meio ambiente urbano em Belo Horizonte. Este texto apresenta algumas ações que fazem parte da copesquisa cartográfica, envolvendo teoria e prática, desenvolvida neste projeto que está vinculado ao programa "IND.LAB _ Laboratório Nômade do Comum".

PALAVRAS-CHAVE: 1. tecnopolítica; 2. movimentos sociais e ambientais; 3. natureza urbana.

\section{URBAN NATURE AND TECNOPOLÍTICAS INDISCIPLINARES}

\section{ABSTRACT}

This paper presents the project "Natureza Urbana" developed by the CNPq research group called "indisciplinary / UFMG" collaborating with multiple actions with social and environmental movements in defense of the quality of the urban environment in Belo Horizonte. This paper presents some actions that are part of cartographic co-reasearch involving theory and practice developed in this project that is linked to "IND. LAB_ Laboratório Nômade do Comum" program.

\footnotetext{
${ }^{1}$ Professora do Curso de Arquitetura da EAUFMG e líder do Grupo de Pesquisa do CNPQ denominado INDISCIPLINAR sediado na Escola de Arquitetura da UFMG. e-mail: natacharena@gmail.com

${ }^{2}$ Octavio Mendes é graduando na escola de arquitetura da UFMG e atualmente é pesquisador do programa Indisciplinar-UFMG, pelo edital Jovens Talentos oferecido pela CAPES.

${ }^{3}$ Professor da Escola de Arquitetura da Universidade Federal de Minas Gerais (UFMG). e-mail: marcelo.maia@gmail.com marcelo.maia@gmail.com
} 
KEYWORDS: 1. technopolitic; 2. social and environmental movements; 3. urban nature.

\title{
URBANA NATURALEZA Y TECNOPOLÍTICAS INDISCIPLINARES
}

\begin{abstract}
RESUMEN
Este artículo presenta el proyecto "Natureza Urbana", desarrollado por el grupo de investigación CNPq llamado "indisciplinary / UFMG" colaborar con múltiples acciones con los movimientos sociales y ambientales en defensa de la calidad del medio ambiente urbano en Belo Horizonte. Este paper presenta algunas de las acciones que forman parte de copesquisa cartográfica que implica la teoría y la práctica, desarrollada en este proyecto que está vinculado al programa "IND.LAB _ Laboratório Nômade do Comum".
\end{abstract}

PALABRAS CLAVE: 1. tecnopolitica; 2. Los movimientos sociales y ambientales; 3. naturaleza urbana.

\section{INTRODUÇÃO}

Pretende-se aqui apresentar o projeto Natureza Urbana que desenvolve um conjunto de ações realizadas pelo Grupo de Pesquisa do CNPq - Indisciplinar/ UFMG - englobando ensino, pesquisa e extensão. Este grupo atua em relação direta com movimentos sociais, ambientais e culturais que lutam em defesa do meio ambiente urbano.

Acredita-se que a metrópole é a nova fábrica e, portanto, é o lugar da produção das forças vivas expropriadas cotidianamente pelo sistema produtivo do capitalismo contemporâneo que atua intensamente na metrópole biopolítica. Expropria-se, tanto a produção em comum, coletiva e criativa, quanto os bens comuns urbanos, mais especificamente os bens comuns naturais (parques, praças e afins).

Um imenso depósito de riqueza comum é a metrópole mesma. A formação das cidades modernas, tal como explicam os historiadores da cidade e da arquitetura, esteve intimamente vinculada ao desenvolvimento do capital industrial. A concentração geográfica dos trabalhadores, a proximidade dos recursos e de outras indústrias, dos sistemas de comunicação e de transportes, assim como as demais características da vida urbana, são elementos necessários para a produção industrial. Ao longo dos séculos XIX e XX, o crescimento das cidades e das qualidades do espaço urbano estiveram determinados pela fábrica industrial, por suas necessidades, 
ritmos e formas de organização social. Sem dúvida, hoje assistimos a um deslocamento da metrópole industrial para a metrópole biopolítica. E na economia biopolítica existe uma relação cada vez mais intensa e direta entre o processo de produção e o comum que constitui a cidade. Desde então, a cidade não é somente um habitat urbanizado feito de edifícios, ruas, subterrâneos, parques, sistemas de esgoto, e cabos de conexão, mas sim também uma dinâmica viva de práticas culturais, circuitos intelectuais, redes afetivas e instituições sociais. Estes elementos do comum contidos nas cidades não somente são pré-requisitos da produção biopolítica, mas também são resultado; a cidade é a fonte do comum e o receptáculo por onde este flui. (...) Uma lente para reconhecer a riqueza comum da metrópole e os esforços para privatiza-la proporciona a ela uma economia da propriedade imobiliária urbana, um campo que precisa uma urgentíssima desmistificação. (HARDT e NEGRI, 2011, p.166)

Acreditando-se que há um imenso depósito de riqueza comum nas metrópoles atuais e que estas riquezas devem ser preservadas, as ações deste grupo tiveram início em fevereiro de 2013, com participação efetiva na teia formada ao redor do movimento Fica Ficus, que surgiu para lutar pela preservação da alameda de ficus numa região importante da cidade de Belo Horizonte. Desde então, muitas conexões entre o grupo de pesquisa e outros grupos e movimentos sociais aconteceram.

Entre 2013 e 2015, com a intensificação dos movimentos multitudinários contra os processos de urbanização neoliberal no Brasil, constituiu-se uma rede de apoio mútuo que vem compartilhando experiências ativistas tanto da Região Metropolitana de Belo Horizonte, quanto movimentos de outras regiões do país e do mundo, como por exemplo, movimento Parque Augusta (São Paulo) ou militantes em defesa do Parque Gezi (Turquia).

Figura 1: Foto de militante da luta em defesa do Parque Gezi na Turquia trocada durante período de intensa atividade tanto no Movimento Fica Ficus quanto no Parque Gezi.

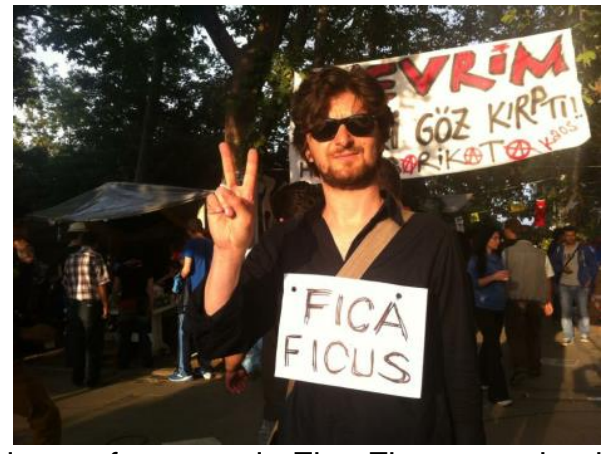

FONTE: Fotos trocadas na fanpage do Fica Ficus no primeiro semestre de 2013. 
Neste processo, já em início de 2015, criou-se a Rede Verde, da qual o grupo Indisciplinar é um dos atores. A Rede Verde emerge em Belo Horizonte conectando movimentos como Salve a Mata do Planalto ou Criação do Parque Jardim América contra o Projeto de Emenda à Lei Orgânica (PELO) de Belo Horizonte, que propunha mudanças nas regras de ocupação das áreas verdes da cidade. De autoria da prefeitura, a proposta PELO no 7/2014 permitiria a instalação de equipamentos públicos em praças, parques, reservas ecológicas e espaços tombados. A aprovação desta lei permitiria que se destruísse mais de 1 milhão de metros quadrados de áreas verdes urbanas. Observa-se a contradição de uma proposta desta quando assistimos à transferência cotidiana de lotes públicos para uma empresa criada pelo próprio Estado denominada PBH Ativos.

Acredita-se que parques, praças, jardins, áreas de preservação ambiental são fundamentais para a qualidade ambiental nas metrópoles e garantem uma vida mais saudável para todos. Além disto, defende-se a importância da multiplicação destes locais coletivos nos quais os cidadãos possam viver parte das suas vidas em espaços de convívio que não sejam necessariamente shoppings, instituições privadas, condomínios fechados, dentre outros.

Como parte desta rede, o grupo Indisciplinar atua auxiliando na organização de um conjunto de ações que possam qualificar o debate em defesa da produção do comum urbano, tanto no que diz respeito aos processos de produção biopolítica afetiva considerado por Hardt e Negri (2011) como "comum artificial", quanto no que diz respeito à preservação e incentivo dos bens comuns com foco na natureza urbana, denominados pelos autores como "comum natural".

\section{Conjuntura político-teórica}

Dentro do contexto contemporâneo, apresenta-se uma questão que possui caráter de urgência: é preciso atuar contra-hegemonicamente à lógica de expropriação dos espaços verdes nas cidades. Desde 1972, quando data a Conferência de Estocolmo, o tema ambiental apresenta-se como urgente para se 
pensar o desenvolvimento urbano no âmbito mundial. Porém, visto as diferentes posições e os conflitos geopolíticos acerca do modelo de desenvolvimento a se adotar, no Brasil pouco se obteve de efetivo a partir de tal conferência.

Segundo Monte-Mór (2008), o impacto real de uma consciência que dissolva a dicotomia campo/cidade sobre o ambiente construído nas aglomerações metropolitanas ainda deixa ainda muito a desejar. É bastante comum compreender as áreas urbanas como espaços mortos e ao mesmo tempo considera-se que é campo de estudo dos arquitetos, urbanistas, cientistas sociais e afins. Por outro lado, as áreas consideradas rurais seriam as regiões ameaçadas pelo desenvolvimento e, portanto, deveriam ser defendidas e preservadas, tornando-se área de pesquisa e prática dos ecologistas e ambientalistas. Esta dicotomia campo $\mathrm{X}$ cidade prejudica um avanço teórico e/ou prático nos modos de imaginar e propor cidades nas quais o território urbano, e seu ambiente construído, fosse também pensado dentro de uma lógica ambiental, não somente entendendo que é preciso mais árvores, praças e parques, mas sim, que todo o espaço poderia possuir uma rica biodiversidade entranhada e hibridada nos seus "concretos". Acredita-se, portanto, que se fugirmos desta lógica dicotômica, poderíamos abrir um vasto campo para reverter a lógica da urbanização extensiva pela lógica da naturalização extensiva (MONTE-MÓR, 2008).

A ideia de que a terra é ilimitada e que deve ser explorada para se fazer justiça social deve ser implodida tanto do ponto de vista científico quanto político. Recentes estudos demonstram que a condição de precariedade ambiental nas metrópoles (com a falta de água e o aumento da temperatura) tende a piorar e a alcançar índices desastrosos.

Além da dicotomia clássica entre cidade e campo, dentro do próprio universo do urbanismo, também há uma outra frente dicotômica que prejudica o avanço de políticas públicas que melhorem a qualidade de vida nas cidades. Esta outra dicotomia diz respeito às diferentes pautas básicas entre movimentos sociais, que defendem o desenvolvimento a todo custo dentro da lógica "tudo para todos", e movimentos ambientalistas, que alertam "não há planeta B", contra o projeto desenvolvimentista que vem destruindo o planeta. Hardt (2012), relatando 
criticamente sua participação na Conferência das Nações Unidas sobre Mudanças Climáticas em Copenhague (2009), aponta para o problema desta dicotomia criada pelas diferenças entre as pautas e formas de ativismo dos movimentos ecológicos (em defesa do comum material/natural) e os movimentos anticapitalistas/antineoliberais (em defesa do comum relacionado aos trabalhos que envolvem a colaboração e a criatividade humana do capitalismo imaterial que produz conhecimentos, imagens, códigos, afetos, relacionamentos sociais, etc.):

\begin{abstract}
As diferenças políticas primárias entre os movimentos, a meu ver, como as antinomias que até certo ponto se sustentam por trás deles, decorrem do fato que eles focam em formas distintas do comum, formas que têm qualidades dissimilares. Por um lado, para os movimentos da mudança climática e ecológicos em geral, o comum se refere primariamente à Terra e seus ecossistemas, inclusive a atmosfera, oceanos, rios e florestas, bem como todas as formas de vida que interagem com eles. Movimentos sociais anticapitalistas, por outro lado, geralmente entendem o comum em termos de produtos do trabalho e criatividade humanos, que compartilhamos, tais como ideias, conhecimentos, imagens, códigos, afetos, relacionamentos sociais e coisas do tipo. Esses bens comuns estão se tornando cada vez mais centrais na produção capitalista - um fato que tem uma série de consequências importantes para os esforços de conservação ou reforma do sistema capitalista, assim como aos projetos de resistir a ele ou derrubá-lo. Como primeiras aproximações, se podem chamar esses dois campos de: comum ecológico e comum social/econômico; ou comum natural e artificial, - embora essas categorias rapidamente se mostrem insuficientes. (HARDT, 2012)
\end{abstract}

Apesar (ou por causa) do avanço do capitalismo contemporâneo sobre os bens comuns da metrópole, aos poucos configuram-se novas lutas em defesa dos comuns urbanos, sejam eles artificiais ou naturais. Alertando contra o processo acelerado de degradação ambiental urbana, surgem e crescem movimentos pelo verde em todo mundo. Mas estes movimentos surgem atualmente como multitudinários, hibridando o discurso ambiental ao social já que, a cada dia, percebe-se com muita nitidez que o neoliberalismo atua nas metrópoles (e em todo território urbano, o que engloba também o campo) expropriando o comum. Não há mais como esconder que esta lógica de expropriação do comum está na base do Estado-capital Imperial e que esta dicotomia vem aos poucos perdendo o sentido, ou seja, os movimentos sociais, ambientais e também os culturais, sabem que é preciso somar as forças englobando a defesa de todos os comuns, tanto os naturais 
quanto os artificiais. É neste sentido que a luta biopolítica das resistências multitudinárias vem se tornando fortemente hibridada por diversos movimentos com pautas múltiplas demonstrando que a luta pela biodiversidade da natureza urbana envolve fortemente o desejo de manutenção e ampliação dos espaços de sociabilidade e encontro cidadão.

\begin{abstract}
Em todo o mundo, vide Parque Gezi (em Istanbul), Gamonal (na Espanha), Fica Ficus, Mata do Planalto, Parque Jardim América (em BH), Parque Cocó (em Fortaleza), Ocupa Estelita (em Recife), ou Parque Augusta (em São Paulo), vemos surgir uma multidão de singularidades e grupos de ativistas, artísticos, de moradores locais e vizinhos, população de rua e comerciantes, universitários e pesquisadores, todos interessados em recuperar o debate político sobre a cidade e a construção, com ação direta, do ambiente que pertence às suas vidas cotidianas. Pra falar do óbvio, a democracia representativa já não mais representa o cidadão comum e vem deixando de lado os interesses de todos para garantir o interesse do mercado que financia o Estado e suas campanhas políticas que garantem a permanência de grupos no poder. Contudo, a sociedade se rebela, e faz isto atualmente, em grande parte, resistindo coletivamente por meio de redes conectadas globalmente, nacionalmente e localmente. O espírito imanente da multidão (conceito negriano que não é povo-estado, nem massa-mercado) encara o Império de frente e exige democracia real e o direito de ter os seus bens comuns administrados autônoma e coletivamente. Estas novas organizações ativistas trazem a frescura da coleção subjetiva das diferenças e a pauta ampliada para além do direito ao verde urbano. O mais interessante é que estes movimentos são horizontais, sem lideranças definidas, e possuem uma dinâmica de articulação, que, por ser rizomática, é impossível de ser cooptada. Vemos o Estado-capital na tentativa desesperada de se aproximar destes movimentos para capturar a sua dinâmica de máquina de guerra que tanto incomoda o Aparelho de Estado (pra usar termos bem deleuzeanos). A autonomia e a autogestão é tudo o que o Estado-capital não pode suportar. (RENA, 2014)
\end{abstract}

Assim, dentro deste ambiente teórico e prático que envolve a preservação e a produção do comum, como um todo, que surge o projeto Natureza Urbana.

\title{
OBJETIVOS
}

Toda produção do conhecimento das pesquisas extensionistas do grupo Indisciplinar têm como objetivo principal gerar tecnologia social. Neste sentido, os processos de investigação partem do encontro cotidiano entre universidade, movimentos sociais, culturais e ambientais envolvidos nas lutas territoriais e desdobram-se em múltiplos campos de ação compartilhados em rede: participação 
em reuniões, representações em Ministério Público, qualificação do debate para audiências públicas, produção de monografias, dissertações de mestrado, teses de doutorado, TCCs, projetos de pesquisa e extensão, disciplinas que participam do cruzamento destes projetos com os movimentos, produção de artigos científicos, eventos e ocupações culturais. O grupo vem atuando tecnopoliticamente também no design, no desenvolvimento e na manutenção de wikis, blogs, fanpages, mapas georreferenciados, projetos gráficos, infográficos, fanzines, cartilhas, dentre outros.

Portanto, o objetivo geral do grupo de pesquisa Indisciplinar é realizar ações que buscam criar, experimentar e aplicar processos que democratizem e sensibilizem a informação e qualifiquem as lutas pelo comum. Assume-se uma posição política na qual a produção de conhecimento e o ativismo se sobrepõem ao cotidiano acadêmico e das lutas gerando uma metodologia sistêmica de trabalho que busca atuar de forma tecnopolítica contra o urbanismo neoliberal.

\section{METODOLOGIA}

A metodologia de ação do projeto Natureza Urbana parte sempre da participação do grupo de pesquisa nas dinâmicas políticas, sociais e espaciais vigentes. Ao longo dos últimos 4 anos, muitas ações extensionistas foram realizadas junto a movimentos ambientais, sociais e culturais envolvendo apoio tecnopolítico como: construção de fanpages, manifestos, mapas georreferenciados, atos festivos, cartografias coletivas, preparação de apresentações para audiências públicas, documentação para representações realizadas no Ministério Público, etc.

\section{Copesquisa cartográfica}

Acredita-se ser possível utilizar o método cartográfico através da produção de cartografias emergentes enquanto ação de investigação engajada (mas não ideológica), ou seja, enquanto copesquisa militante (mas não partidária).

Segundo Bruno Cava (2012), copesquisa não separa teoria da prática e agencia atravessamentos de múltiplas ordens. Não dissocia sujeito de objeto e se 
faz de maneira aberta a mudanças de perspectiva, possuindo uma tendência $p$ na qual a produção de conhecimento e o ativismo se sobrepõem. Pretende-se, com este método (ou anti-método), investigar a composição política dos sujeitos e seus modos de auto-organização.

Já a cartografia passa pelo conceito de rizoma em Deleuze e Guattari (1995) e nos aproxima de processos cartográficos nos quais predominam características do rizoma enquanto potências em fluxo que se encontram, conectando mundos e modos de vida.

\begin{abstract}
Um rizoma não começa nem conclui, ele se encontra sempre no meio, entre as coisas, inter-ser, intermezzo. A árvore é filiação, mas o rizoma é aliança, unicamente aliança. A árvore impõe o verbo "ser", mas o rizoma tem como tecido a conjunção "e...e...e....". Há nesta conjunção força suficiente para sacudir e desenraizar o verbo ser. [...] mover-se entre as coisas, instaurar uma lógica do $E$, reverter a ontologia, destituir o fundamento, anular fim e começo. [...] É que o meio não é uma média; ao contrário, é o lugar onde as coisas adquirem velocidade. Entre as coisas não designa uma correlação localizável que vai de uma para outra e reciprocamente, mas uma direção perpendicular, um movimento transversal que as carrega uma e outra, riacho sem início nem fim, que rói suas duas margens e adquire velocidade no meio. (Deleuze e Guattari, 1995, p. 48-49).
\end{abstract}

O rizoma é o processo de conhecimento da realidade sob forma não arborescente - busca das raízes profundas que fundamentam os fatos. O rizoma, ao contrário da árvore, dá-se desordenadamente, faz-se num crescimento horizontal e na superfície, proporcionando uma entrada na realidade, sem portas preestabelecidas. O rizoma não admite normas regulares e desenvolve-se de nó a nó, de tema a tema, de conceito a conceito, aleatoriamente. Traçar um percurso rizomático seria estar sempre entre e, assim, destituir o fundamento, a ontologia, anular o começo e o fim, desenvolver pensamentos como ervas na superfície, livres, adquirindo velocidade, conformando espaços lisos, não arborescentes.

A crítica ao transcendente ${ }^{4}$ ou ao invisível e ontológico, criada através do rizoma, é uma construção que combate o pensamento ocidental hierarquizado, com

\footnotetext{
${ }^{4}$ Em Deleuze, transcendental se diferencia de transcendência. Enquanto o primeiro seria um plano de imanência, que rejeita as idéias de consciência e de sujeito, o segundo supõe um sujeito ou um objeto a ser transcendido. $O$ transcendental não remeteria nunca a algo que não exista no mundo, ou seja, o transcendental do campo de imanência não se confunde com o transcendental clássico da filosofia, seja ele platônico ou kantiano, porque não pressupõe algo exterior.
} 
base na representação do mundo ${ }^{5}$, e que separa o mundo real do mundo ideal ou representado e abstrato-arborizado. Segundo Deleuze e Guattari, a árvore dominou a realidade no ocidente "e todo o pensamento ocidental, da botânica à anatomia, mas também a gnesiologia, a teologia, toda a filosofia... o fundamento raiz, ground, roots e fundations" (DELEUZE e GUATTARI, 1995, p. 29).

\begin{abstract}
Ser rizomorfo é produzir hastes e filamentos que parecem raízes, ou, melhor ainda, que se conectam com elas penetrando no tronco, podendo fazê-las servir a novos e estranhos usos. Estamos cansados da árvore. Não devemos mais acreditar em árvores, em raízes ou radículas, já sofremos muito. Toda cultura arborescente é fundada sobre elas, da biologia à lingüística. [...] O pensamento não é arborescente, e o cérebro não é uma matéria enraizada nem ramificada. [...] Muitas pessoas têm uma árvore plantada na cabeça, mas o próprio cérebro é muito mais uma erva do que uma árvore. (DELEUZE e GUATTARI, 1995, p.25).
\end{abstract}

Para Deleuze, não existe um modelo, nem mesmo um guia, mas apenas um referente, ou seja, um cruzamento a ser operado sem cessar. O autor ressalta a relação intrínseca entre o rizoma e a microbiologia do cérebro — órgão humano que funciona como uma rede de conexões e de informações sincrônicas. "O que nos inspira hoje não são os computadores, é a microbiologia do cérebro: este se apresenta como um rizoma, mais como uma grama do que como uma árvore" e,

\footnotetext{
${ }^{5}$ Para Deleuze, esta representação vai se tornar possível em Platão, quando este inaugura e desenvolve uma teoria da Idéia. Mas o que Platão declara "tem uma motivação moral em toda sua pureza, ou seja, um desejo de eliminar os simulacros, os fantasmas, as diferenças livres, as distribuições nômades, enfim, o incomensurado, o disforme, não classificável, toda a malignidade que contesta e insere um paradoxo tanto na noção de modelo quanto na de cópia" (DELEUZE, 1988:420). Quando Platão subdivide o mundo entre sensível e inteligível, ele situa no mundo sensível o mundo das imagens (reflexos e sombras) e o mundo dos corpos (dos corpos vivos e dos objetos que o homem produz). Mas, para atingir seu objetivo, que era o de constituir um saber, ele precisaria evitar o mundo dos objetos em constante mudança. Então, ele só constrói sua filosofia sobre o que for do universo das idéias, do pensamento, do inteligível. O mundo dos corpos, da matéria e do sensível vai ser enquadrado pelo filósofo no campo das artes. Os objetos do mundo sensível se submeteriam aos objetos do mundo inteligível, tornando-se cópias do mundo superior das idéias. Inicia-se assim o que Platão vai chamar de mundo da representação. Ocorre que alguns objetos que fazem parte desse mundo sensível não se submetem ao mundo inteligível - por exemplo as sombras e os reflexos - e, portanto, serão chamados pelo filósofo de simulacros, e nenhum saber poderia se constituir sobre eles.
} 
desta forma, "todo o novo pensamento traça ao vivo no cérebro sulcos desconhecidos, torce-o, dobra-o, fende-o." (DELEUZE, 1992, p.186).

A cartografia e a decalcomania existem, para Deleuze e Guattari, como um dos princípios do rizoma, pois "um rizoma não pode ser justificado por nenhum modelo estrutural ou gerativo. Ele é estranho a qualquer idéia de eixo genético ou de estrutura profunda" (DELEUZE e GUATTARI, 1995, p.20). Partindo do eixo genético, os princípios existentes são da ordem do decalque que, por sua vez, é reprodutível ao infinito. O decalque pode ser um registro como mera uma tentativa de reprodução. "O decalque já traduziu o mapa em imagem, já transformou o rizoma em raízes e radículas. Organizou, estabilizou, neutralizou as multiplicidades segundo eixos de significâncias e de subjetivação que são os seus" e, de forma pouco criativa e frutífera "injeta redundâncias e as propaga" (DELEUZE e GUATTARI, 1995, p.23).

A partir do decalque é possível traçar um mapa rizomático. Esse é o método do rizoma que se propõe para pensar e agir cartograficamente, abrindo a possibilidade de um pensamento-ação suscetível, capaz de receber modificações a qualquer tempo. A idéia de se fazer o mapa é se opor ao decalque, mas, simultaneamente, o completando. Se, por um lado, o decalque está "inteiramente voltado para a experimentação ancorada no real” (DELEUZE e GUATTARI, 1995, p. 22), o mapa, por sua vez, viabiliza o estudo da presença das forças intensivas que atravessam o campo de imanência do cotidiano e da vida.

\begin{abstract}
... contribui para a conexão dos campos, para o desbloqueio dos corpos sem órgãos, para a sua abertura máxima sobre um plano de consistência. Ele faz parte do rizoma. O mapa é aberto, é conectável em todas as suas dimensões, desmontável, reversível, suscetível de receber modificações constantemente. Ele pode ser rasgado, revertido, adaptar-se a montagens de qualquer natureza, ser preparado por um indivíduo, um grupo, uma formação social. Pode-se desenhá-lo numa parede, concebê-lo como uma obra de arte (DELEUZE e GUATTARI, 1995, p.22).
\end{abstract}

O mapa/cartografia, inserido na ordem do rizoma, acomoda uma de suas principais características: "a de ter múltiplas entradas" (DELEUZE e GUATTARI, 1995, p.22). Os autores, porém, se perguntam se não seria imprópria a oposição entre o mapa e o decalque, entre $o$ liso e o estriado, entre os espaços 
desterritorializados e os territorializados, já que um atravessa o outro, refazendo-se sempre em instâncias diferentes, como num processo das multiplicidades, onde toda substância, ao se dividir, muda a sua natureza. "Não é próprio do mapa poder ser decalcado? Não é próprio do rizoma cruzar as raízes, confundir-se às vezes com elas? [...] Mas o inverso é também verdadeiro, é uma questão de método: é preciso sempre projetar o decalque sobre o mapa" (DELEUZE e GUATTARI, 1995, p.22-23).

Deste modo, associando a ideia de rizoma ao método cartográfico, entendese aqui a cartografia não somente como método da geografia clássica territorial, mas como tática micropolítica cotidiana composta pela ação tecnopolítica, ou seja, um fazer insurgente, dinâmico, sempre processual e criativo.

Unindo o método da copesquisa ao método cartográfico, acredita-se na realização de uma copesquisa cartográfica como um método de investigação que envolve uma experiência cotidiana, dissolvendo as relações entre micro e macropolítica, assim como entre sujeito pesquisador e objeto pesquisado.

\section{Tecnopolíticas e constituição de redes}

Tecnopolíticas, assim como propostas pelo $15 \mathrm{M}$, são entendidas como processos de uso tático e estratégico de dispositivos tecnológicos para a organização do movimento, comunicação e ação coletiva. As redes tem servido para orientar ações que se distribuem tanto pelas redes digitais quando pelos espaços físicos públicos e comuns. Em nossas copesquisas cartográficas em prol da natureza urbana, adota-se uma série de ações tecnopolíticas, que possuem a capacidade de transmitir informações e permitir a ação coletiva, para assim agregar sentido próprio à ação de pesquisa e para também ativar e potencializar impulsos transformativos na (e da) metrópole biopolítica.

\section{RESULTADOS E PROCESSOS}




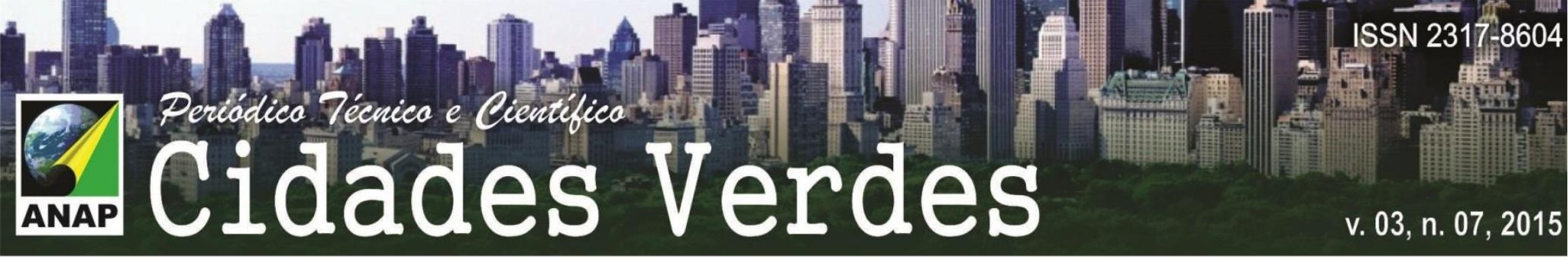

Toda produção tecnopolítica utilizada pelo projeto Natureza Urbana envolve o método da copesquisa cartográfica em diversas frentes de atuação. A seguir alguns exemplos destas ações.

\section{Coleção Posters/Cartilhas}

Em 2014 produziu-se uma Coleção de Posters/cartilhas (FIG.1) para expor no evento Cartografias do Comum (agosto de 2014) realizada pelo Indisciplinar com diversos parceiros ativistas da cidade. Um destes posters/ cartilha tinha adotou como tema "Natureza Urbana" e englobou todas as ações realizadas junto ao movimento Fica Ficus até então.

Figura 1: Poster da Cartilha Indisciplinar "Natureza Urbana".

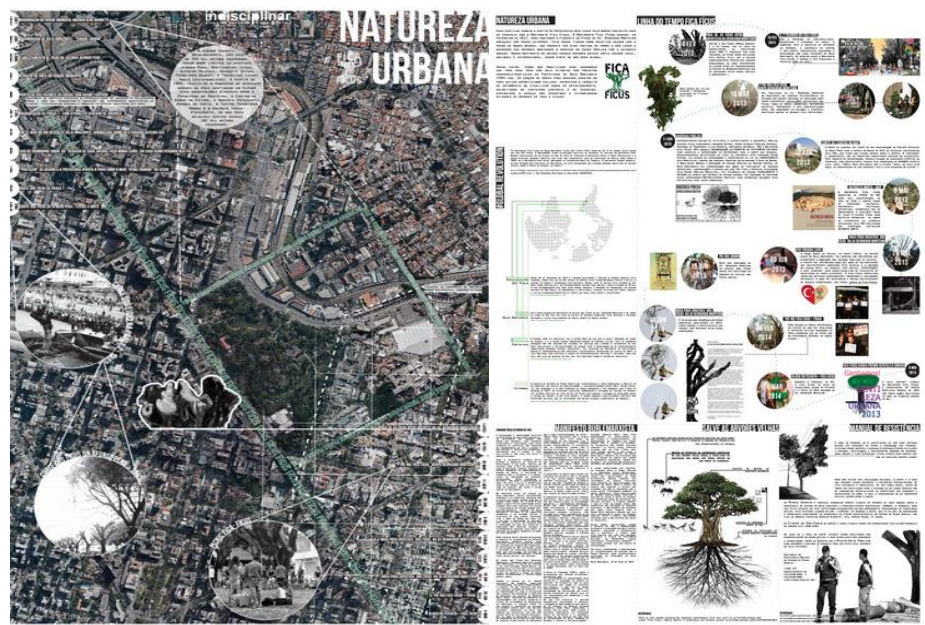

FONTE: Elaboração própria. A cartilha encontra-se disponível em:

http://blog.indisciplinar.com/infograficos/

\section{Disciplina UNI 009 - Cartografias Emergentes III}

Durante este primeiro semestre letivo de 2015 dentro da disciplina UNI 009 Cartografias Emergentes III que é aberta para toda a graduação da UFMG, envolvendo atores e grupos de diversos movimentos sociais e ambientais da cidade, realizou-se um amplo mapeamento do verde e da situação destas áreas na região metropolitana de Belo Horizonte. 


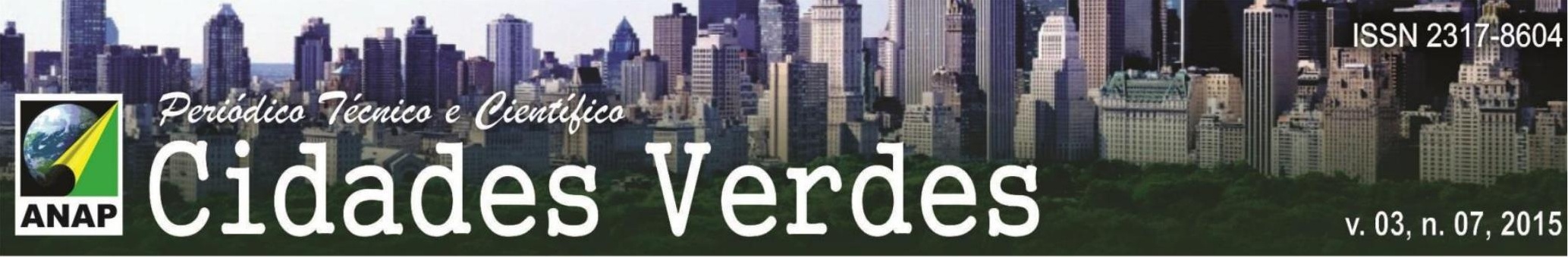

Durante o processo de trabalho, a turma elaborou um mapa territorial georreferenciado denominado Natureza Urbana (FIG. 4) contendo as seguintes etapas: 1. Leitura de textos teóricos e pesquisa de projetos ambientais de referência; 2. Preparação da informação com mapas e dados e definição de algumas categorias iniciais para o mapeamento das áreas; 3. Mobilização no bairro Jardim América (local de uma das lutas envolvidas na Rede Verde) para a realização do mapa colaborativamente; 4. Preparação do ato Ocupa Cultural Salve o Parque Jardim América;

Figura 3: Flyer do Evento "Ocupa Cultural', realizado no Parque Jardim América. e foto do mapeamento colaborativo sendo realizado no evento Ocupa Cultural.
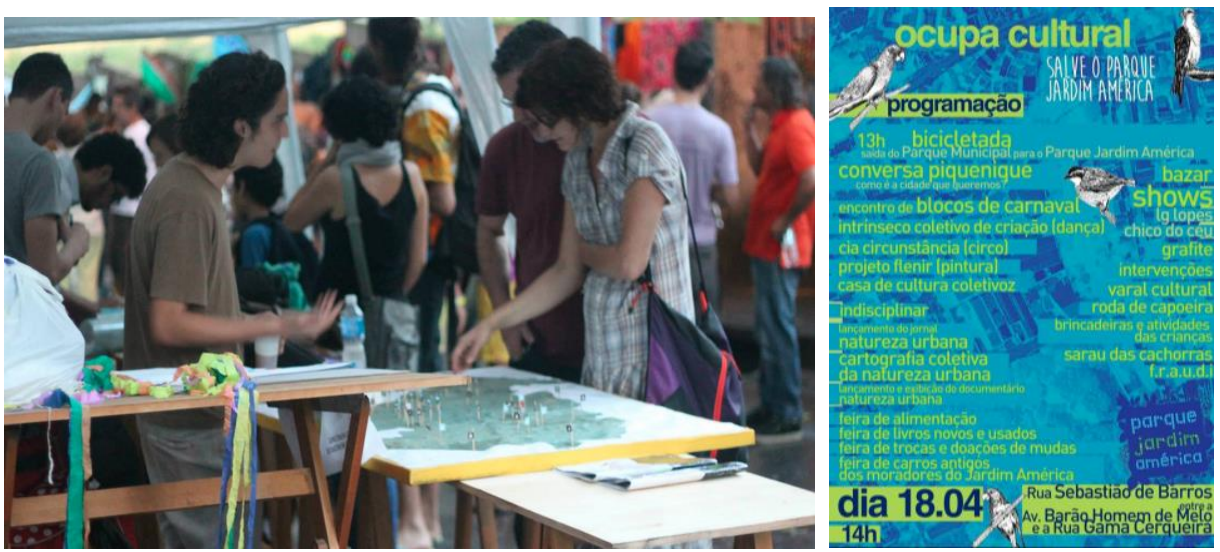

5. Visita ao território, conversas com atores da comunidade, realização do mapa colaborativo (FIG. 3); 6. Transferência dos dados coletados no mapeamento presencial nos territórios das comunidades e dos grupos envolvidos para a plataforma crowdmap - naturezaurbana.crowdmap.com -; 7. Realização de um workshop no laboratório da universidade com a comunidade do território mapeado para ensiná-los a trabalhar com a plataforma georreferenciada; 8. Produção de peças gráficas que contenham infográficos e diagramas que sintetizem todo 0 processo. 


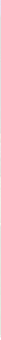

Figura 4: Mapa Crowmap utilizado no mapeamento da disciplina UNI009 - Cartografias Emergentes.
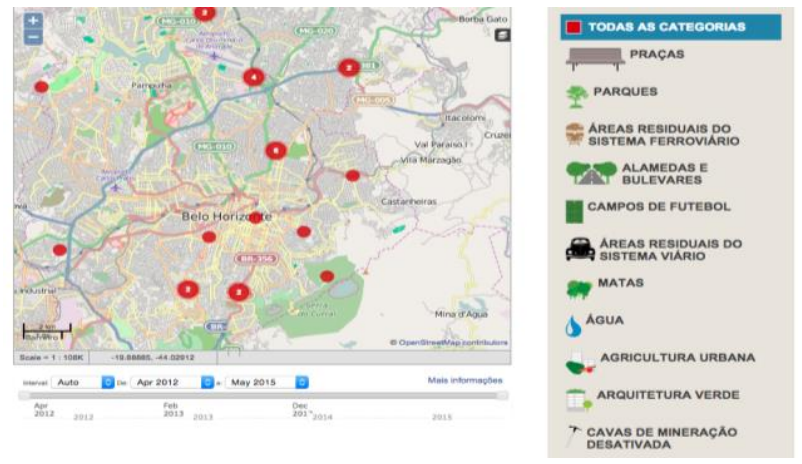

\section{Mapeamento ENVI-MET}

Um outro método de análise do contexto vegetado na cidade foi a utilização do programa ENVI-Met@ (FIG.5) que é possibilitada a simulação do ambiente térmico nos dois cenários: com a região verde e sem ela. Para tal, estabeleceu-se uma parceria com o LABCON - Laboratório de Conforto Ambiental da Escola de Arquitetura UFMG, sob a orientação da professora doutora Eleonora Sad. Os dados gerados são importantes para comprovar a perda de qualidade ambiental caso se eliminasse mais áreas verdes na cidade.

Figura 5: Exemplo de utilização do ENVI-MET.

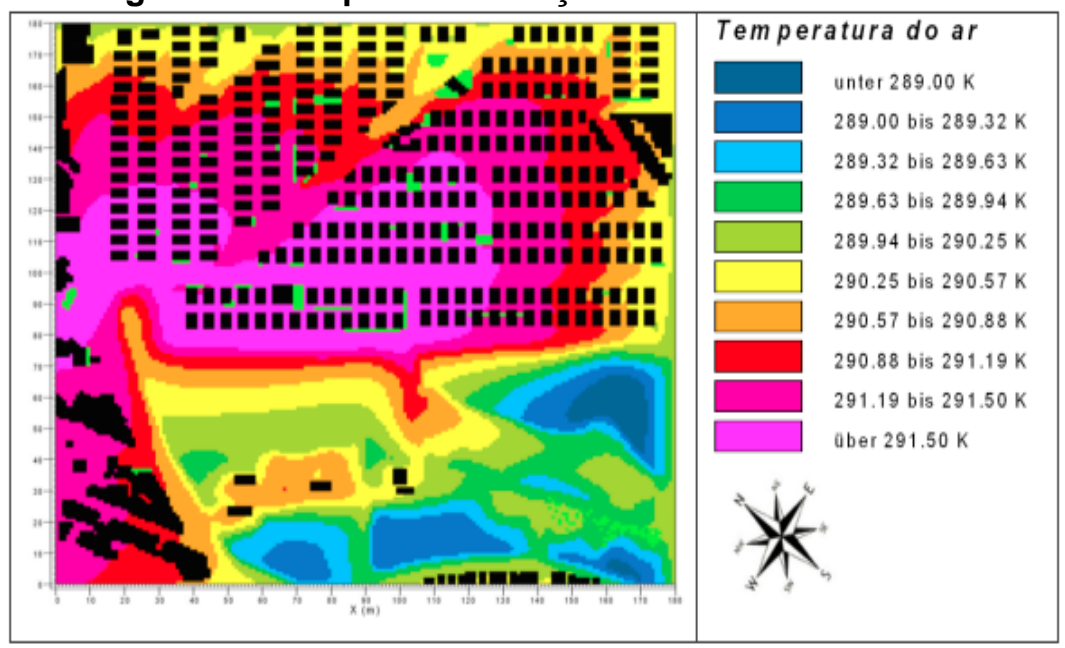

Fonte: FRANCISCO, Rúbia C. Augusta. CLIMA URBANO: UM ESTUDO APLICADO A BELO HORIZONTE, MG. 


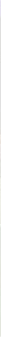

\section{Formação da Rede Verde}

Realizou-se a criação de mídias sociais (FIG.6) para a Rede Verde com o intuito de divulgar ações e facilitar o contato com outros movimentos.

Figura 6: Fanpage da Rede Verde

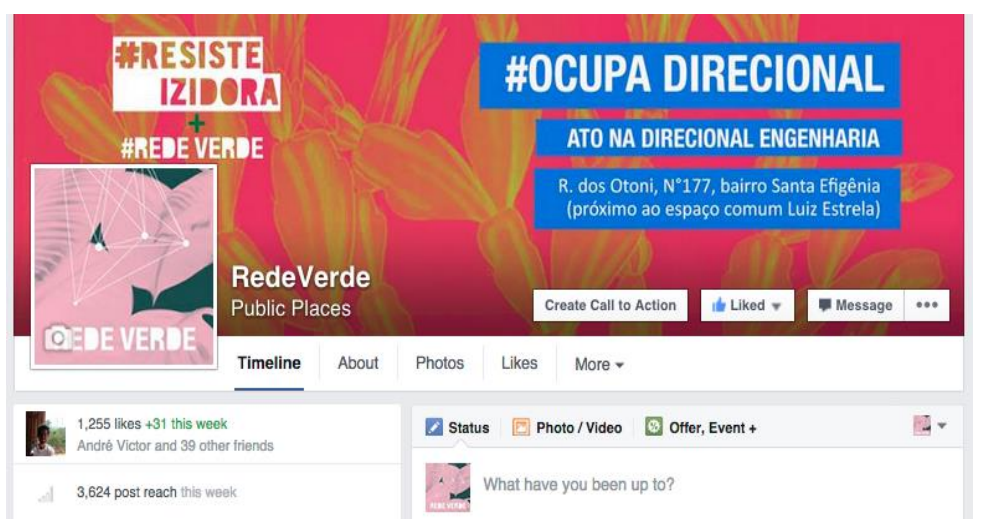

Com o objetivo de facilitar essa veiculação de imagens, foi também desenvolvido um Manual de Diretrizes Gráficas (FIG.7) para as mídias sociais da Rede Verde que pudesse ser utilizado por todos os movimentos envolvidos.

Figura 7: Manual de diretrizes gráficas da Rede Verde.

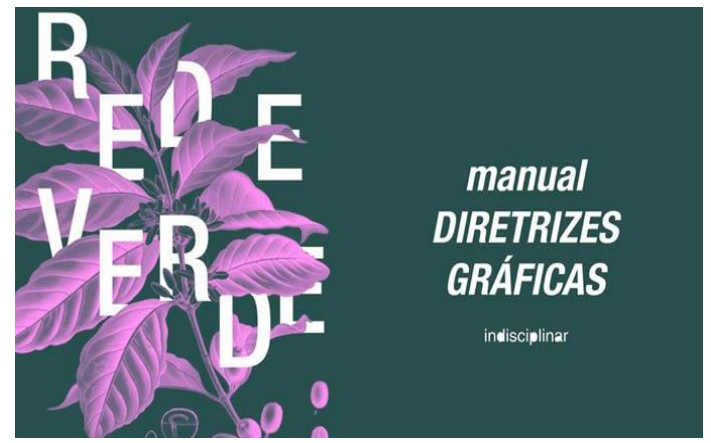

FONTE:<www.wiki.indisciplinar.com/index.php?title=Manual_de_diretrizes_gráficas\%3A_RedeVerde>

Jornal Natureza Urbana e Documentário Natureza Urbana 


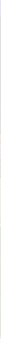

Realizou-se um documentário denominado Natureza Urbana (FIG.8) contando com a fala de diversos pesquisadores a ativistas de diversos movimentos ambientais.

Figura 8: e Screenshot do documentário Natureza Urbana, com a fala da ativista do Parque Jardim América, Rose Aquino.

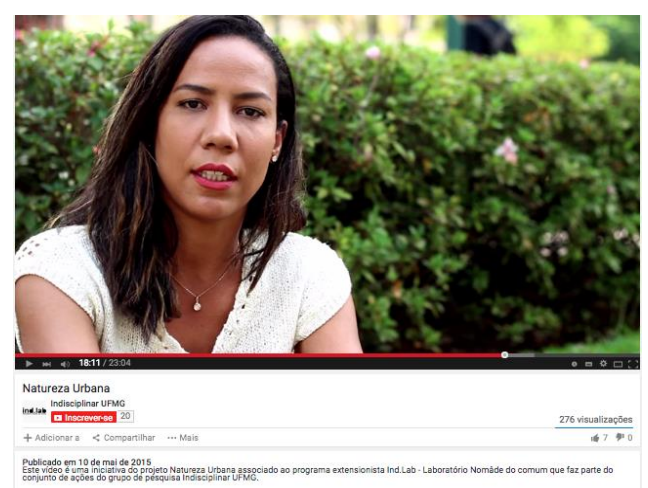

FONTE:<https://www.youtube.com/watch?v=nO3pxUhdvuM>

Criou-se, também, o Jornal Natureza Urbana (FIG.9) que veicula e a propaga os ideais da Rede Verde.

Figura 9: Capa do jornal Natureza Urbana

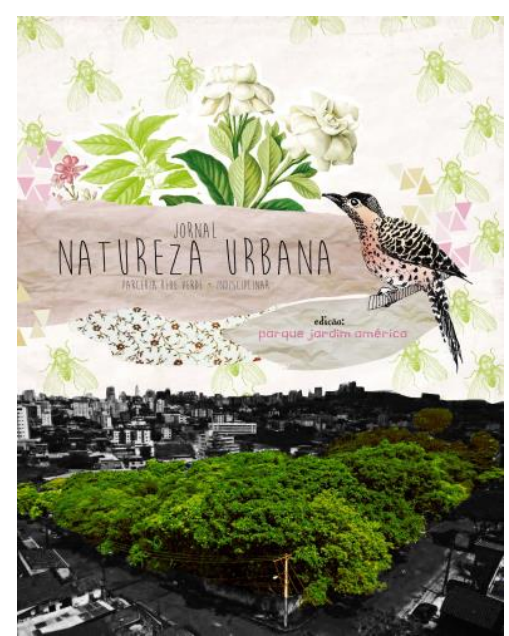

FONTE: <www.issuu.com/octaviomendes/docs/jornal> 


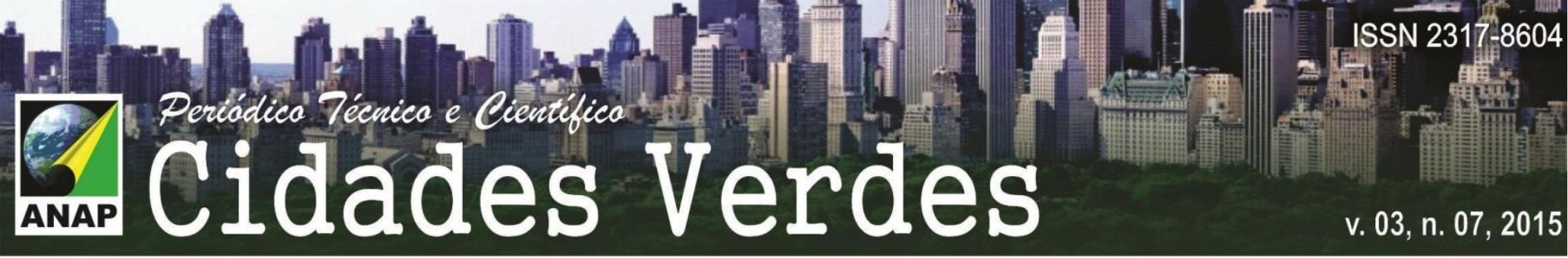

\section{CONCLUSÃO}

O grupo de pesquisa Indisciplinar, através desta copesquisa cartográfica e de sua produção tecnopolítica indisciplinar, aposta nas resistências positivas que lutam pela preservação do que restou dos bens comuns naturais nas metrópoles e ao mesmo tempo, atua nos processos políticos pela manutenção e ampliação destes espaços urbanos como espaços comuns, que possam ser autogestionados pelos cidadãos como um bem compartilhado, e assim, possa se tornar possível não somente destituir o avanço Estado-capital na expropriação dos bens comuns urbanos (via urbanismo neoliberal), como também a constituição de novos campos de luta que agregam diversas frentes de trabalho e atuação tecnopolítica, envolvendo um novo modo de imaginar e construir a metrópole (via urbanismo tático).

\section{REFERÊNCIAS}

DELEUZE, Gilles. Conversações. Rio de Janeiro: Editora 34, 2000.

Foucault. São Paulo: Brasiliense, 2005. DELEUZE, Gilles. A ilha deserta e outros escritos. São Paulo: lluminuras, 2006.

DELEUZE, Gilles \& GUATTARI, Félix. Mil Platô s. Capitalismo e Esquizofrenia. Rio de Janeiro: Editora 34, 1995. 5 volumes.

HARDT, Michael; NEGRI, Antonio. Commonwealth. El projecto de una revolución del común. Madrid: Akai, 2009.

HARDT, Michael. As duas faces do Apocalipse: uma carta de Copenhague. Revista Lugar Comum. 47- , 2012

MONTE-MÓR, Roberto Luís de. Urbanização extensiva e lógicas de povoamento: um olhar ambiental. http://www.ufpa.br/epdir/images/docs/paper34.pdf

RENA, Natacha. Parque Augusta e as resistências verdes. Blog Indisciplinar, UFMG, Belo Horizonte, 2014. disponível em: <http://wiki.indisciplinar.com/index.php?title=Rede_Verde> acesso em 29/05/2015.

$<$ www.issuu.com/octaviomendes/docs/jornal> acesso em 29/05/2015.

$<$ https://www.youtube.com/watch?v=nO3pxUhdvuM> acesso em 29/05/2015. 